\title{
Analysis on the Evolution of China's Cultural Industry Policy from Perspective of Advocacy Coalition Framework
}

\author{
Zupeng Yang ${ }^{1, *}$ and Yuan $\mathrm{Su}^{2}$ \\ ${ }^{1}$ School of Government Management, Beijing Normal University, Haidian District, Beijing 100875, China \\ ${ }^{2}$ School of Education, Renmin University of China, Haidian District, Beijing 100086, China \\ *Corresponding author.Email:945412642@qq.com
}

\begin{abstract}
This study attempts to use the advocacy coalition framework theory to analyse the evolution process of China's cultural industry policy and explain the two advocacy coalitions existing in China's cultural industry policy subsystem, one is the government led coalition, the other is the social coalition. The study found that policy learning is the main way of cultural industry policy change, in which the endogenous learning of government led coalition is the main, taking into account the learning of two coalitions. Government officials are both coalition advocates and policy brokers in the cultural industry subsystem. As a platform for communication and exchange among the main bodies of the cultural industry, the professional forum needs to be further widened and improved. The research shows that in the development process of China's cultural industry, the government led coalition and social coalition have formed a certain consensus, and mutual cooperation has achieved win-win results.
\end{abstract}

Keywords: Cultural industry policy, Advocacy coalition framework theory, Policy subsystem, Policy learning

\section{INTERPRETATION OF ADVOCACY COALITION FRAMEWORK THEORY}

The advocacy coalition framework theory, proposed by American policy scholars Sabattier and Jenkins, is the development of three policy models: progressivism, interest organization competition and ideological conflict. It is mainly used to explain the dynamic change mechanism of social policy. [1] According to this theory, when people focus on an important policy issue, a policy subsystem on this issue will be formed. In this policy subsystem, there will be multiple advocacy coalitions (generally 1-4), and the actors (participants) in the policy subsystem belong to these different advocacy coalitions. The key to distinguishing advocacy coalitions is the difference of their policy core beliefs. The belief system is divided into three levels: the core belief system, the policy core belief system and the outer belief system. [2] The core belief system of an advocacy coalition is the most difficult to change, involving the most basic concepts, such as worldview. The policy core belief is also difficult to change. It is the basic strategy to realize the core belief. The outer belief system is easy to change. It is a series of more specific means and measures. According to this theory, the following points deserve attention:(1) There are many advocacy coalitions in the policy subsystem, and their status is not equal. A policy introduction is the manifestation of the dominant advocacy coalition belief system in the subsystem. However, the status of advocacy coalition is not invariable. If the weak advocacy coalition seizes the opportunity, it may also reverse its status. (2) The policy subsystem is always in dynamic change. If an advocacy coalition is in a hegemonic and dominant position for a long time, the policy subsystems within the surface framework are in a relatively stable state. The policy subsystem under significant change reflects a competitive relationship between coalitions. (3) The advocacy coalition framework theory generally regards the policy process of ten years and more as a whole and holds that policy change is mainly based on policy learning within and between advocacy coalitions and intervention from external systems. General policy changes and adjustments mainly occur within the subsystem, and external events become the motivation affecting the main policy changes.

\section{DEVELOPMENT AND EVOLUTION OF CHINA'S CULTURAL INDUSTRY POLICY}

\subsection{Budding Period (1978-1991)}

From the end of 1970 to the mid-1980s, with the end of the "Cultural Revolution" and the proposal of reform and opening up, China's national economy gradually recovered and achieved preliminary development. The reform of the economic system promoted changes in the cultural and ideological fields. The public began to break through the 
shackles of the extreme "left" cage, actively explore new knowledge and ideas and create a new life, social and cultural consumption has recovered, and the cultural industry has begun to sprout and achieve a certain degree of recovery and development. In 1979, Guangzhou Oriental Hotel opened the first music teahouse in China, which became the symbol of the rise of new China's cultural market.[3] It is worth noting that the industrial nature of some cultural industries in this period was recognized by the government. In 1985, The State Council forwarded to the National Bureau of Statistics the Report on the Establishment of tertiary Industry Statistics, culture and art as a component of the tertiary industry was included in the national production statistics. In 1988, the Ministry of Culture and the State Administration for Industry and Commerce jointly issued the Notice on Strengthening the Management of Cultural Market, which adopted the concept of "cultural market" in government documents for the first time. In 1989, The State Council approved the establishment of the Cultural market Administration Bureau in the Ministry of Culture, and the national cultural market management system began to be established. The state began to participate in cultural market activities as cultural legislator and law-enforcer. In 1991, The State Council approved and transferred the Report of the Ministry of Culture on Several Economic Policies for Cultural Undertakings, formally proposing the Cultural and economic Policy.

\subsection{Early Stage of Development (1992-2001)}

In 1992, the 14th National Congress of the Communist Party of China explicitly proposed to build a socialist market economic system with Chinese characteristics, and the establishment of the market economic system laid a foundation for the healthy development of cultural industry. In the same year, The State Council issued the Decision on Accelerating the Development of the Tertiary Industry, officially including the cultural industry in the tertiary industry, and positioning the cultural sector from a financial expenditure-oriented sector to a production-oriented sector, which made policy and system preparations for the development of the cultural industry. With the rapid development of cultural industry, cultural demand is also growing, and it is developing in the direction of entertainment, diversification and participation. The 14th National Congress of the Communist Party of China called for "actively promoting the reform of the cultural system, perfecting the economic policies related to cultural undertakings, and flourishing socialist culture", and further arrangements for the reform of the cultural system were made in the Government Work Report of the first Session of the eighth National People's Congress held in 1993. In October 1996, the sixth Plenary Session of the 14th CPC Central Committee adopted the Resolution of the CPC Central Committee on Several Important Issues concerning Strengthening socialist Spiritual and Cultural Construction, stressing that "reforming the cultural system is the fundamental way out for the prosperity and development of cultural undertakings". In 2001, the General Office of the CPC Central Committee and The General Office of the State Council forwarded several Opinions on Deepening the Reform of The Press, Publication, Radio, Film and Television Industry, proposing that under the premise of strengthening the leadership of the $\mathrm{CPC}$, more than 70 cultural groups, including China Radio, Film and Television Group and China Publishing Group, should be established under the theme of development to accelerate the integration and structural adjustment of the cultural market.

In the initial formative period of the development of cultural industry, the relationship between the cultural industry development and the ideology dissemination has gradually changed from passive to active by the Party and the government, and the development trend of diversified cultures under the dominance of unitary culture has been formed. However, as the cultural market has not been established, cultural products are uneven.

\subsection{Rapid Expansion Period (2002-2011)}

With China's accession to the WTO, the international competition in politics, culture, economy and other fields is becoming increasingly fierce, and the important strategic position of the cultural industry is further highlighted. The state has issued a series of policies and measures to accelerate the reform of the cultural system and promote the development of the cultural industry. Developing cultural industry has become an important part of China's national economic and social development. In 2002, the 16th National Congress of the Communist Party of China scientifically distinguished cultural undertakings and cultural industries in the official documents of the Communist Party of China for the first time, clearly expounded the dialectical relationship that interrelated and different between them, and stressed that "we should pay attention to public welfare cultural undertakings on the one hand and operational cultural industries on the other hand", which is of milestone significance in the development of cultural industries.

\subsection{Comprehensive Improvement Period (since 2012)}

After 2012, while actively promoting the development of state-owned cultural enterprises, the state has formulated a series of effective policies and measures to promote the rapid development of non-public cultural enterprises. Thanks to the good development environment and conditions at home and abroad, China's cultural industry has shown a strong momentum of sustained growth and achieved comprehensive improvement after 15 years of hard work. On the basis of "Cultural and Related Industries Classification 2002", China has adjusted the statistical standard of cultural industry. After 2012, the most obvious change in China's cultural industry structure is the rapid development of the new cultural industry with the Internet 
as the carrier, which has increasingly become a new growth point of the cultural industry. NPC and CPPCC in 2015, "Internet plus" appeared in the government work report, which aroused heated debate in various circles of society. In April 2017, the Cultural Development and Reform Plan of the Ministry of Culture during the 13th Five-Year Plan period clearly stated that during the 13th Five-Year Plan period, a number of national-level cultural industrial parks with obvious gathering and radiation functions should be cultivated. On April 2, 2018, the National Bureau of Statistics revised and promulgated the Classification of Culture and Related Industries (2018), adding subcategories of activities that meet the definition of culture and related industries.

Table 1. Overview of cultural industry policies

\begin{tabular}{|c|l|}
\hline Release Date & \multicolumn{1}{|c|}{ Policy } \\
\hline 1988 & Notice on Strengthening the Administration of Cultural Market \\
\hline 1991 & Report of the Ministry of Culture on Several Economic Policies Concerning Cultural Undertakings \\
\hline 2001 & Outline of the Tenth Five-Year Plan for Economic and Social Development \\
\hline 2005 & Opinions on Deepening Reform of the Cultural System \\
\hline 2006 & Outline of the National Cultural Development Plan for the Eleventh Five-Year Plan Period \\
\hline 2012 & Cultural Industry Multiplication Plan during the 12th Five-Year Plan Period \\
\hline 2014 & Guiding Opinions of the Ministry of Finance on Promoting the Development of Characteristic Cultural Industries \\
\hline 2015 & Opinions of the CPC Central Committee on the Prosperity and Development of Socialist Literature and Art \\
\hline 2015 & Opinions of the CPC Central Committee on the Prosperity and Development of Socialist Literature and Art \\
\hline 2016 & Circular of The State Council on Printing and Distributing the 13th Five-Year Plan for Tourism Development \\
\hline 2018 & Implementation Plan for the System and Restructuring of Central Cultural Enterprises \\
\hline
\end{tabular}

\section{ANALYSIS ON THE EVOLUTION OF CULTURAL INDUSTRY POLICY BASED ON ADVOCACY COALITION FRAMEWORK THEORY}

\subsection{Composition of Advocacy Coalition}

According to the advocacy coalition framework theory, China's cultural industry policy exists as a subsystem. For a long time, China has been implementing the state arranged cultural model. The embryonic stage from 1978 to 1992 is the concentrated embodiment of this management model. There is only a single advocacy Coalition - government led coalition in the cultural industry policy subsystem, and its members are mainly the CPC Central Committee, the State Council, the ministry of culture and relevant ministries and commissions, local governments, etc. The common core idea of the advocacy coalition is: government led promotion of the development of cultural industry. The reform of cultural industry should break the government's practice of arranging cultural development. It should first be carried out within the cultural department system, put forward the concept of "cultural market", and fully implement "public institutions and enterprise management". Public institutions with conditions in the cultural system can change from public institutions to enterprises. At this stage, there is only a single government led coalition in the cultural industry subsystem, and there is no opposition and conflict of other advocacy coalitions. Therefore, there is little resistance to policy implementation. In the practice of cultural industry, there are phenomena such as the influx of music teahouses and cassette tapes and recorders in Guangzhou Oriental Hotel. After 1992, the cultural industry entered the marketoriented stage and was included in the third sector. A new advocacy coalition appeared, that is, the social advocacy coalition of the cultural industry. Its members are social capital market, cultural intermediary market, foreign exchange companies and so on. Its core belief is that the cultural market is a diversified economy, and the cultural industry run by individuals and enterprises is a formal supplement and improvement to the state and government. In addition, the experience of the development of cultural industry in many foreign developed countries is worth learning from. There are two advocacy coalitions in the cultural industry policy subsystem, which have different core beliefs (as shown in Table 2). The previous stable state was broken, the competition between coalitions began to appear, and the interest groups related to culture began to exert influence on the national cultural industry policymaking, trying to provide possibilities and opportunities for them to participate in the cultural industry and obtain benefits. The cultural monopoly of large Internet enterprises led by Alibaba by means of M \&amp; A and equity investment is a typical example. It reveals the fierce game between the social advocacy coalition led by Alibaba and the government led coalition led by the industrial development of China's cultural sector. [4] 
Table 2. Core belief system

\begin{tabular}{|c|l|l|}
\hline Indicator & \multicolumn{1}{|c|}{ Government-Led Coalition } & \multicolumn{1}{c|}{ Socially-Led Coalition } \\
\hline Constitute & $\begin{array}{l}\text { the Central Committee of the Communist Party of China, The } \\
\text { State Council, the Ministry of Culture and relevant ministries } \\
\text { and commissions }\end{array}$ & $\begin{array}{l}\text { social capital markets, cultural } \\
\text { intermediary markets and foreign } \\
\text { exchange companies }\end{array}$ \\
\hline $\begin{array}{c}\text { The Core } \\
\text { Ideas }\end{array}$ & $\begin{array}{l}\text { the government takes the lead in promoting the development of } \\
\text { cultural industry }\end{array}$ & $\begin{array}{l}\text { Individuals and businesses complement } \\
\text { the culture of government }\end{array}$ \\
\hline $\begin{array}{c}\text { Value } \\
\text { Priority }\end{array}$ & Unification & Diversification \\
\hline
\end{tabular}

On the whole, although there is competition in the cultural industry subsystem, it is not fierce enough. It is basically in a relatively stable state, and the government led coalition has an advantage. The several changes of "national advance and national retreat" and "national advance and national retreat" in the management mode of "bird's nest" are an excellent example. Finally, the state took over the "bird's nest". From another perspective, competition means that each coalition has a sense of crisis. In order to maintain the advantages of policy quality and efficiency, the government led coalition must learn from. This makes policy change possible.

\subsection{Policy Learning -- the Main Way of Cultural Industry Policy Evolution}

According to the advocacy coalition framework theory, policy learning is the main way of policy change, which occurs in the outer belief system. It is a process of continuous exploration and debugging for the members of the policy subsystem to realize their core policy concepts. [5] Policy learning can be divided into endogenous learning and exogenous learning. Endogenous learning reflects initiative, while exogenous learning reflects school level passivity. Relevant scholars have found that active learning mainly occurs within coalitions, while inter coalition learning is more passive. [6]

In the cultural industry policy subsystem, there are both endogenous and exogenous learning. For the government led coalition, in the process of cultural industry development, it has recognized the inherent ills of the development model of cultural industry under the planned economic system; The government manages too much, unifies too much, and the financial burden is too heavy. Therefore, we should actively seek policy changes, constantly deepen understanding, broaden the source channels of funds for the cultural industry, and encourage all sectors of society to participate in and support the development of the cultural industry. Exogenous learning among coalitions is also increasing, although it is passive. At present, the strength of social coalitions is constantly strengthening. For example, the overall scale of private enterprises is expanding and their position in the national economy is gradually improving. However, from the overall perspective, the development of China's cultural industry is unbalanced and insufficient. From the data in Table 3, it can be seen that the operating revenue of state-owned cultural industry listed companies is as high as 1817.952 billion yuan, accounting for $72.58 \%$ of the total revenue of all cultural industry listed companies; The net profit was 163.317 billion yuan, accounting for $72.38 \%$ of the total net profit of all listed companies in the cultural industry; The operating revenue of private cultural industry listed companies was 655.185 billion yuan, accounting for $26.15 \%$ of the total revenue of all cultural industry listed companies, and the net profit accounted for $28.71 \%$ of the total net profit of all cultural industry listed companies. [7]

Table 3. Number and proportion of cultural industry listed companies with different ownership in 2016

\begin{tabular}{|c|c|c|}
\hline Classification & Number & Proportion \\
\hline State-owned & 88 & 25.9 \\
\hline Private & 181 & 53.2 \\
\hline Relative state ownership & 2 & 0.6 \\
\hline Private relative holding & 38 & 11.2 \\
\hline The foreign capital enterprise & 16 & 4.7 \\
\hline Sino-foreign joint venture & 15 & 4.4 \\
\hline
\end{tabular}

At the same time, China's cultural industry investment system is not mature, and it is difficult to rely on the market to realize the mutual assistance between the cultural industry and the capital market. Therefore, the government fiscal policy plays an important role in the investment process and effectively guides the capital market. Therefore, it is essential to strengthen communication and learning between coalitions. In addition, the cultural industry has its own characteristics. For example, to operate the cultural tourism industry, we must learn and follow relevant policies and regulations. To this end, the State Administration of Culture has issued the Revitalization Plan of Cultural Industry, the Guiding Opinions on Promoting the Combined Development of Culture and Tourism, and the Decision of the CPC Central Committee on Several Major Issues concerning Deepening the Reform of cultural System and Promoting the Great Development and Prosperity of Socialist Culture. These policies undoubtedly take building a "cultural power" as the national long-term development strategy and put the promotion of the integrated development of cultural industry and tourism in a prominent position. [8]

At present, the main way of China's cultural industry policy change is policy learning, which reflects the subtle repair, routine change and gradualism of cultural industry policy under the national system. 


\subsection{Influence of External Variables of Cultural Industry Policy Subsystem}

\subsubsection{Relatively Stable Parameters}

It mainly includes four parameters: the basic attributes of the problem field, the basic distribution of natural resources, social and cultural values and social structure, constitutional institutions or order. [9] According to relevant research, the relatively stable parameters take the coalition opportunity structure as the bridge, which affects the operation of the policy subsystem.[10] Relatively stable parameters are difficult to change in a short time, which may play a positive role in promoting policy change or hinder policy change. Taking the basic attributes of the problem field as an example, China has different understanding of the cultural industry and is mostly treated as public welfare undertakings. In practice, cultural organizations or institutions are mostly regarded as public institutions, such as local performance and artistic creation units, which do not welcome the development of cultural organizations or enterprises other than public ownership. From the macro level, it ignores the ownership structure of the development of cultural industry, which hinders the change of cultural industry policy. Taking cultural value and social structure as an example, relevant studies cite the viewpoint of sociologist Xueyi Lu that Chinese society has been divided into ten strata, the basic components of modern strata have been provided, the modern social stratum order has been established, and a modern social stratum structure has been formed in China. At the same time, it uses the development example of American cultural industry to draw the conclusion that social stratification has guiding significance for the development of cultural industry. This change of social structure will promote the continuous evolution of cultural industry policy. [11]

\subsubsection{Impact of external events}

At present, the changes of social and economic environment, the guidance of public opinion and other subsystem decisions have a great impact on the cultural industry policy. First, the impact of social and economic environment changes. Since the founding of new China, sports has been mentioned for the first time in the government work report delivered by Premier Rongji Zhu at the second session of the Ninth National People's Congress. In 2003, the decision of the CPC Central Committee on Several Issues concerning the improvement of the socialist market economic system clearly put forward the issue of cultural industry. In 2007, several Opinions of The State Council on Accelerating the Development of service Industry proposed specific measures for the development of cultural industry. These macroeconomic policies have played a fundamental guiding role in the specific measures for the development of cultural industry. In addition, the successful hosting of the Beijing Olympic Games and the upcoming Beijing Winter Olympic
Games, as major events, have also had a far-reaching impact on the development of China's cultural industry. A number of cultural industry policies issued in 2016 are an example. Second, the impact of public opinion guidance. If public opinion leads to a secondary coalition, the importance of this coalition will be highlighted. The social coalition in the cultural industry policy subsystem can appear as a competitive coalition, which is due to the guiding role of public opinion. Private enterprises are the product of China's reform and opening up, and have occupied "half" of China's economy. It is the function of public opinion guidance that makes it understand and enter the cultural industry on a large scale. Under the influence of public opinion, the status of the cultural industry in the future social coalition will further rise and become more competitive. Third, other subsystems play a promoting role. For example, the tourism policy subsystem will have an impact on cultural tourism, and then promote the development of the whole cultural industry.

\subsection{The role of Policy Brokers and Professional Forums}

\subsubsection{Policy Brokers}

According to the advocacy coalition framework, policy brokers are concerned with finding reasonable compromises to mitigate violent conflicts or are primarily concerned with keeping political conflicts within acceptable limits and reaching reasonable solutions to the problem.[12] Policy brokers are usually government officials, courts and other actors. They often appear as a third party to make each party compromise and finally get out of the policy deadlock through mediation. In many cases, it's difficult to distinguish the roles of government officials as policy brokers and coalition members (advocates). In this paper, government officials initially appear as coalition members with their own core beliefs, and then their identity is transformed into policy brokers. The integration of multiple roles is a common phenomenon in the current social transformation process. What is noteworthy is that no matter what role the government plays, it has the will to maintain the stability of subsystems. In the process of dealing with the problem of cultural tourism industry, the government played an important role as a policy broker, stipulated that the price of tickets should not rise and punished price fraud, alleviated the contradiction and finally calmed the incident.

\subsubsection{Professional Forums}

According to the theory of advocacy coalition framework, professional forums can help coalitions learn from each other and get out of policy deadlock. Relevant research lists several characteristics of successful professional forums proposed by Sabatier; Professional forums include all stakeholders, who should build trust, and no one is willing 
to accept policy gridlock. It can be seen that the professional forum is actually a platform for multi-party negotiation and communication, and there are policy brokers here. This paper argues that academic forums can also be included to explore a rational way of cultural industry policy development through the exchange and collision of various viewpoints. At present, there are many cultural industry policy seminars, whose views can provide certain support for various coalitions. Take the 2010 World Expo as an example, before the Expo was held, several seminars for relevant professionals were held and various discussions were held.

\subsection{Intermediary Mechanism -- the Degree of Formula Needed for Policy Change of Cultural Industry}

Practice has proved that although China has introduced several cultural industry policies in recent years, the development of cultural industry itself is still in a primary stage. In culture industry planning policies, for example, in China have issued the "the cultural construction of the eleventh five-year plan" of the ministry of culture cultural reform and development planning "twelfth five-year" period, the ministry of culture "much starker choices-and graver consequences-in" period of cultural industry development planning ", the culture industry planning policies is dominant in the development of cultural industry policy, and other cultural industries policy making should be based on. These plans have formed some consensus. For example, in terms of development goals, from the 11th Five-Year Plan to the 13th Five-Year Plan, the pursuit of cultural innovation and culture of the whole people are driven by the construction of long-term cultural management, and cultural centers, cultural training, cultural industry intermediary, cultural media and other industries are developing rapidly. At the same time, there are some common and sober understanding of the existing problems, such as the current cultural industry in China is not high, the structure is not reasonable, the market theme vitality and creativity is a little weak, the effective supply capacity of products needs to be strengthened, the cultural industry supply side structural reform needs to be promoted, and so on.

\section{CONCLUSION}

Based on the theory of advocacy coalition framework, this paper analyzes the evolution and changes of China's cultural industry policy. The subsystem of China's cultural industry policy includes two advocacy coalitions, one is governmentled coalition, the other is social coalition. The system is in a relatively stable state, which mainly highlights the role of government-led coalition.

Policy learning is the main way of policy change in cultural industry, in which the endogenous learning of governmentled coalitions is the main one, and the learning between the two coalitions is taken into account. In addition, the intervention of external variables can not be ignored. Macroeconomic policies promote the change of cultural industry policies, so we should further strengthen the understanding of the nature of culture, and constantly explore the function of cultural popularization and industrialization.

In the subsystem of cultural industry, government officials are both advocates and policy brokers and should give full play to their functions as policy brokers. As a platform for communication, professional forum needs further demineralization and improvement. Especially in the process of cultural industry development, both the government-led coalition and the social coalition form a certain consensus.

\section{REFERENCES}

[1] Zhangbao Yu. The Framework and Application of Advocacy Coalition in Policy Theory [J]. Journal of Xiamen University (Philosophy and Social Sciences),2009(01):26-31. (In Chinese)

[2] Jiade Zhu, Zimao Li. The evolution logic of China's higher education fee System in the past 60 years: Based on the Support Coalition Framework [J]. Teaching and Educating,2010(18):4-9. (In Chinese)

[3] Zhou Fan, Yu Yang. The development process and achievements of China's cultural industry during the forty years of Reform and opening up [J]. Journal of Shandong University (Philosophy and Social Sciences). 2018, (04) (In Chinese)

[4] Yan Zhang, Qin Wang, Suyan Zhang. Practice and experience of retail business Model innovation and development path under the Background of Internet -Based on Alibaba case analysis [J]. Contemporary economic management,2020,42(12):16-22. (In Chinese)

[5] Lin Chen. Theoretical Exploration on Policy Learning [J]. Monthly Journal of Learning,2020(24):7273. (In Chinese)

[6] Chuncheng Wang. Framework of Advocacy Coalition: Analysis and Application [D]. Changchun: Jilin University,2010:56,60,66-67. (In Chinese)

[7] Xuefang Xie, Zhipeng Zang. Comparative study on the control force between state-owned capital and private capital of listed cultural industry companies [J]. Academic forum,2018,41(01):141-149. (In Chinese)

[8] Rui Huang, Chaowu Xie, Yongquan Li. Analysis on the evolution and effectiveness of China's cultural tourism industry policy: Based on policy Samples from 
2009 to 2018 [J]. Tourism Tribune, 201,36(01):27-40. (In Chinese)

[9] Jiying Zhang, Baiying Sun. Advocacy coalition framework: dynamic evolution, application characteristics and application evaluation [J]. Journal of LanZhou university (social sciences),2020,48(06):22-

32. (In Chinese)

[10] Chuncheng Wang. Framework of Advocacy Coalition: Analysis and Application [D]. Changchun: Jilin University,2010:56,60,66-67. (In Chinese)
[11] Yiyang Zhao, Yimin Liu. Review on the stratification of Sports Society [J]. Shandong Sports Science and Technology,2007(1):8-10. (In Chinese)

[12] Liping Fu, Kaibo Xu, Lanping He. The choice of policy broker: A study on the path of reform of medical reform system-A Case study of Xining Model [J]. Journal of Gansu Administrative College,2020(06):2334+125. (In Chinese) 